\title{
Anticellular PEO coatings on titanium surfaces by sequential electrospinning and crosslinking processes
}

\author{
Murat Şimşek $^{1} \cdot$ Sevcan Dalkıranoğlu Aldemir ${ }^{2}$ - Menemşe Gümüşderelioğlu ${ }^{1,3}$ (B)
}

Received: 15 May 2019 / Accepted: 6 July 2019 / Published online: 26 August 2019

(C) Qatar University and Springer Nature Switzerland AG 2019

\begin{abstract}
Titanium implants having some superior properties for tissue replacements have been widely used in biomedical fields. However, the implants are vulnerable to bacterial attacks and therefore they must be modified. In this study, two kinds of titanium surfaces, bare (Ti-b) and sandpapered (Ti-p) titanium, were used and electrospinning method was utilized for coating them with poly(ethylene oxide) (PEO) nanofibers with average diameter of $180 \mathrm{~nm}$. In order to obtain insoluble coating, the PEO nanofibers were crosslinked by UV-initiating and crosslinking agent, pentaerythritol triacrylate (PETA), in the presence of UV irradiation at 366$\mathrm{nm}$ wavelength. Fibroblastic MC3T3-E1 preosteoblasts and S. epidermidis bacteria were cultured on these surfaces to investigate their attachment and proliferation behavior. The preosteoblasts cultured on Ti-p exhibited better initial adhesion than that of Ti-b at the end of the $4 \mathrm{~h}$ of incubation period, which reveals the importance of surface roughness. The bacteria adhered and colonized on Ti-b surfaces at the end of the $24 \mathrm{~h}$ of incubation. In contrast, Ti surfaces modified by the PEO nanofibers inhibited cellular and bacterial attachment significantly. This study discloses that electrospinning and subsequent crosslinking of PEO can be evaluated as an effective approach for creating anticellular coatings for Ti implants.
\end{abstract}

Keywords Electrospinning $\cdot \mathrm{PEO} \cdot$ Nanofiber coating $\cdot$ Titanium $\cdot$ Cell adhesion

\section{Introduction}

Biomedical implants are used for reconstituting the functionality of damaged organs or tissues. There is a variety of biomedical implants based on metallic, ceramic, and polymeric materials. Metallic implants can be classified as steels, cobalt/ cobalt alloys, and titanium/titanium alloys. Among them, titanium (Ti) and its alloys have been extensively used owing to their excellent biocompatibility and mechanical properties [1-4]. However, implants may fail because of (i) lack of integration with tissue and (ii) infections that are the consequence of bacterial attachment to the implant surface and the subsequent development of a biofilm. Implant-associated infection

Menemșe Gümüșderelioğlu

menemse@ hacettepe.edu.tr; menemse@gmail.com

1 Department of Nanotechnology and Nanomedicine, Hacettepe University, Ankara, Turkey

2 Department of Biology, and Chemical Engineering, Hacettepe University, Ankara, Turkey

3 Chemical Engineering, Hacettepe University, 06800 Ankara, Turkey is a serious complication since it is not only resistant to natural host defense mechanisms, but also resistant to most antibiotics and antimicrobial treatment [5]. It has been reported that a very large proportion of implant-related infections are caused by Staphylococcus aureus (S. aureus) and Staphylococcus epidermidis (S. epidermidis) [6]. In the last decades, $S$. epidermidis has been the most isolated bacteria from hospital and biomaterial-related infections [7, 8]. S. epidermidis also easily adheres and proliferates on Ti surfaces.

The approaches to reduce protein adsorption which contributes to bacterial attachment and biofilm formation include the modification of surfaces by hydrophilic chains, anticoagulant coatings, phosphorylcholine-modified polymer coatings, and poly(ethylene glycol) (PEG)-based coatings [9-14]. A method to inhibit bacterial attachment by means of highly hydrated biocompatible polymers such as PEG (or polyethylene oxide, PEO) has been a promising approach. The water layer covers the surface, introducing a high activation barrier for bacteria to adhere, and also for proteins to adsorb $[12,15,16]$. It has been reported that the adhesion of many types of bacteria was substantially reduced by immobilized PEG and oligo (ethylene glycol) at implant surfaces [17-19]. The common approaches to immobilize PEG to

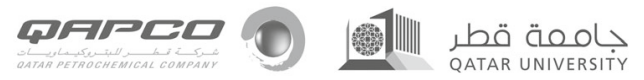


the material surfaces include the covalent coupling of PEG chains [20], physical adsorption of PEG, graft copolymers [21], and plasma deposition methods [22].

Electrospinning which uses electrical forces to generate polymeric fibers with nano-/micro-sized diameters is an effective, cost efficient, and easily applied technique [23, 24]. Electrospun fibers have been successfully used in drug delivery, tissue engineering, and other biomedical applications due to their highly porous structures, high surface area to volume ratio, potential biocompatibility, and high functionality [25-27]. In the literature, although there are limited studies based on coating of Ti implants with electrospun fibers, to the best of our knowledge, no investigation has been demonstrated for PEO nanofiber-coated implant surfaces in terms of cellular/bacterial adhesion. In a recent study, S. aureus adhesion has significantly reduced on the Ti surfaces modified by $\mathrm{PEO} /$ poly(lactide-co-glycolic acid) compared with the unmodified ones [28]. In another study, adhesion and proliferation of osteoblasts were studied on electrospun PLGA or PLGA/collagen fiber-coated Ti discs [4].

In this paper, unlike modifying implant surfaces by techniques requiring high temperatures and chemicals, Ti implants were modified in a very effective way by electrospun PEO nanofibers without the need for an antimicrobial agent or further modifications. The attachment and proliferation of MC3T3-E1preosteoblasts and S. epidermidis on the uncoated and PEO nanofiber-coated Ti surfaces were investigated and compared.

\section{Experimental studies}

\subsection{Coating of titanium implants with PEO nanofibers}

Commercially pure $(99.98 \%)$ titanium strips with $0.2-\mathrm{mm}$ thickness were purchased from BAĞ-SAN Titanium Metal Corporation (Turkey). Some of the Ti strips were sandpapered with 180 grit $\mathrm{SiC}$ papers to compare the effect of surface roughness on fiber stability and cellular adhesion. The strips were then cleaned with ethanol using an ultrasonicator for 15 min. PEO $\left(\mathrm{M}_{v}: 600,000 \mathrm{Da}\right.$, Sigma-Aldrich) powder $(0.4 \mathrm{~g})$ was added into the $10-\mathrm{mL}$ distilled water and the mixture was kept under vigorous magnetic stirring overnight at room temperature to obtain homogeneous PEO solution. After adding 10\% (with respect to PEO wt) crosslinking agent pentaerythritol triacrylate (PETA, Sigma-Aldrich), the resultant solution was further stirred vigorously for $1 \mathrm{~h}$ under shading to disperse PETA. Then, the solution was loaded into 2.5-mL 21-gauge needle and it was placed to a syringe pump (NE 300, New Era Pump Systems) to obtain a steady flow at a flow rate of $0.4 \mathrm{~mL} \mathrm{~h}^{-1}$. A power of $18 \mathrm{kV}$ was applied at a distance of $23 \mathrm{~cm}$ between the tip of the needle and the grounded collector. The PEO fibers were collected for $5 \mathrm{~min}$ on Ti samples $(1 \mathrm{~cm} \times 1 \mathrm{~cm})$ fixed to a stationary collector. The coated Ti surfaces were kept at $37{ }^{\circ} \mathrm{C}$ for 8 days for complete drying of the PEO nanofibers. Then, the fibercoated samples were placed under a high-intensity UV light source (a wavelength of $366 \mathrm{~nm}$, GLT Gase-und Labortechnik Inc.) for crosslinking. The distance between Ti samples and the lamp head was $4 \mathrm{~cm}$. The crosslinking process was realized for 50 min under room conditions. The coated implants were stored in a desiccator prior to further applications. Some of the crosslinked nanofiber-coated samples were kept in distilled water at $37^{\circ} \mathrm{C}$ for $24 \mathrm{~h}$ and then, dried at room temperature to determine whether the fiber coatings were still on the surfaces or not. Ti samples used in the study and their abbreviations are listed in Table 1.

\subsection{Surface characterization}

The surface analysis of the coated and uncoated Ti samples was done by a scanning electron microscope (SEM, Zeiss Evo 50) and atomic force microscope (AFM, Vecoo Multi Mode V-AS-12) operating at tapping mode. Prior to imaging, the samples were coated with gold layer. The average diameter of the fibers was determined from SEM images by using ImageJ software (NIH, Bethesda, MD). The diameters were presented as average \pm standard deviation. The wettability of the samples was assessed by static water contact angle measurements with sessile drop method at room temperature (Kruss DSA 100). The surface roughness of uncoated samples was measured by a perthometer (Mahr, M2).

\subsection{In vitro cell culture experiments}

\subsubsection{Cell seeding and culturing}

Cell culture studies were conducted in sterile 24-well tissue culture polystyrene plates (TCPS, Orange Scientific) in stationary conditions. Prior to cell culture experiments, 24-well plates were coated with Parafilm. Then the coated plates were soaked in $96 \%$ ethanol and placed under UV light during $30 \mathrm{~min}$ for sterilization. Additionally, PEO-coated and uncoated titanium samples $(1 \mathrm{~cm} \times 1 \mathrm{~cm})$ were sterilized under UV

Table 1 Titanium samples used in the experimental studies and their abbreviations

\begin{tabular}{ll}
\hline Abbreviations & Description \\
\hline Ti-b & Bare titanium surface \\
Ti-p & Mechanically polished bare titanium surface \\
Ti-b-PEO & PEO nanofiber-coated Ti-b \\
Ti-b-crPEO & Crosslinked PEO nanofiber-coated Ti-b \\
Ti-p-crPEO & Crosslinked PEO nanofiber-coated Ti-p \\
\hline
\end{tabular}


light for $30 \mathrm{~min}$. Then, the samples were individually placed into single wells of a 24 -well plate. The cell culture studies were carried out by using mouse preosteoblasts (MC3T3-E1, doubling time $33 \mathrm{~h}$, No. RCB1126, Riken Cell Bank) at $37^{\circ} \mathrm{C}$ in a humidified $5 \% \mathrm{CO}_{2}$ atmosphere (Heraeus Instruments). At first, MC3T3-E1 cells were subcultured in flasks using $\alpha$ Minimum Essential Medium ( $\alpha$-MEM, Hyclone) supplemented with $10 \%(\mathrm{v} / \mathrm{v})$ fetal bovine serum (FBS) and $1 \%$ (v/v) penicillin-streptomycin (Biological Ind.). The cells maintained at $37{ }^{\circ} \mathrm{C}$ in a humidified $\mathrm{CO}_{2}(5 \%)$ atmosphere were dissociated with $0.01 \%(\mathrm{v} / \mathrm{v})$ trypsin/10 mM EDTA (Sigma), centrifuged, and resuspended in the medium prior to cell seeding. Thereafter, $1 \mathrm{~mL}$ of cell suspension containing $5 \times 10^{4}$ cells in complete culture medium was added to each well having Ti samples. TCPS without Ti samples was used as control. The culture plates were incubated at $37{ }^{\circ} \mathrm{C}$ in a humidified $5 \% \mathrm{CO}_{2}$ atmosphere.

\subsubsection{Cell viability and microscopic imaging}

The MC3T3-E1 cells on the Ti samples were quantitatively assessed with 3-[4, 5 dimethylthiazol-2-yl]-diphenyltetrazolium bromide (MTT, Sigma) at different culture periods. At selected time intervals (4th, 24th, and 48th hour), the culture medium was aspirated and washed with $600-\mu \mathrm{L}$ phosphate buffer solution (PBS, pH:7.4). A total of $600 \mu \mathrm{L}$ of serumfree culture medium supplemented with $60-\mu \mathrm{L}$ MTT solution (2.5 $\mathrm{mg} \mathrm{mL}^{-1}$ MTT dissolved in PBS) was added to each sample and the incubation was performed at $37^{\circ} \mathrm{C}$ for $3 \mathrm{~h}$. Then, the medium was removed from each well and Ti samples were transferred to another 24-well TCPS. A total of $400 \mu \mathrm{L}$ of $0.04 \mathrm{M} \mathrm{HCl}$ in isopropanol solution was added to each well to dissolve formazan crystals. A supernatant of $200 \mu \mathrm{L}$ was used for measuring optical density at $570 \mathrm{~nm}$ with reference to $690 \mathrm{~nm}$ using a microplate reader (Asys UVM 340). In addition, the stability of the PEO coatings was investigated for longer culture period, i.e., 28 days, by MTT measurements.

The cells attached onto the Ti samples were observed by SEM. This is why Ti samples were removed from the culture medium at the end of $4 \mathrm{~h}$ of incubation and they were gently washed with PBS and then, the cells were fixed with $2.5 \%$ (v/v) glutaraldehyde in 0.1 M Dulbecco's PBS (DPBS) for $30 \mathrm{~min}$. Subsequently, the materials were dehydrated in ethanol series (i.e., 30, 50, 70, 90, and 100\%, respectively) and rinsed with hexamethyldisilazane (HMDS, Sigma). After being completely dried, the samples were mounted on aluminum stubs and coated with gold before morphological observation.

Statistical analysis was performed with Graph-Pad InStat statistic program (GraphPad Software). A Tukey-Kramer multiple comparisons test was applied to determine the significant differences among the groups at $p<0.05$.

\subsection{Bacteria culture}

Bacterial adhesion on Ti surfaces was performed by using S. epidermidis (+) ATCC (American Type Culture Collection $®)$ ) $12228^{\mathrm{TM}} *$ (biofilm-forming strain) and S. epidermidis (-) ATCC@ 35984TM* (not biofilm-forming strain) that were purchased from KWIK-STIK Microbiologics. Bacteria strains were inoculated at $37{ }^{\circ} \mathrm{C}$ in Sheep Blood Agar overnight. On the next day, the produced colonies were inoculated as a single colony in Petri dishes containing Mueller-Hinton agar (Becton Dickinson) at $37{ }^{\circ} \mathrm{C}$ overnight. Then, the bacteria suspensions were prepared from the single colony and were additionally inoculated overnight at $37^{\circ} \mathrm{C}$ so that they reached to logarithmic growth phase. At next step, bacteria suspension (equivalent to a $0.5 \mathrm{McF}$ arland standard) with absorbance value of 0.1 at $600 \mathrm{~nm}$ was prepared in Mueller-Hinton broth. The final inoculum to $5 \times 10^{5} \mathrm{CFU} / \mathrm{mL}$ was accomplished by diluting the $0.5 \mathrm{McF}$ arland suspensions $1: 150$, and subsequent $1: 2$.

Ti samples were sterilized by $70 \%$ ethanol and subsequently UV irradiation for $30 \mathrm{~min}$ and then, placed into 24-well TCPS. A bacteria suspension of $1 \mathrm{~mL}\left(5 \times 10^{5} \mathrm{CFU} / \mathrm{mL}\right)$ was added on each Ti surface for $2 \mathrm{~h}$ of incubation at $37{ }^{\circ} \mathrm{C}$. At the end of the incubation period, nonadherent bacteria were removed from the surfaces by gently washing with sterile normal saline $(0.9 \% \mathrm{w} / \mathrm{v})$ three times. Ti strips with adherent bacteria were put into $1 \mathrm{~mL}$ of sterile normal saline and stirred in vortex additionally to dismount adherent bacteria from the surfaces. After serial dilution, $100 \mu \mathrm{L}$ of the bacterial solution was taken out and plated onto Mueller-Hinton agar. The plates containing bacteria were incubated in an aerobic atmosphere at $37{ }^{\circ} \mathrm{C}$ for $24 \mathrm{~h}$, and then the numbers of the surviving colonies were counted.

The bacterial attachment on Ti surfaces (Ti-b, Ti-b-crPEO) was investigated by using $S$. epidermidis (+) for SEM

Table 2 Optimized electrospinning and crosslinking conditions for the preparation of PEO-coated Ti surfaces

\begin{tabular}{ll}
\hline Electrospinning conditions & \\
Molecular weight of PEO (Da) & 600,000 \\
PEO ratio (w/v, \%) & 4 \\
Crosslinker & PETA \\
Crosslinker ratio (w/w, \%) & 10 \\
Solvent & Distilled water \\
Flow rate $\left(\mathrm{mL} \mathrm{h}^{-1}\right)$ & 0.4 \\
Applied voltage $(\mathrm{kV})$ & 18 \\
Collecting distance $(\mathrm{cm})$ & 23 \\
Crosslinking conditions & \\
Wavelength of UV (nm) & 366 \\
Distance to sample (cm) & 4 \\
Exposure time (min) & 50 \\
\hline
\end{tabular}


observation. Ti samples were sterilized by UV irradiation for $30 \mathrm{~min}$ and then placed into 24-well TCPS. A total of $50 \mu \mathrm{L}$ of bacteria suspension $\left(1 \times 10^{6} \mathrm{cfu} \mathrm{mL}^{-1}\right)$ in tryptic soy broth (Merck) was cultured on the Ti surfaces for $24 \mathrm{~h}$ at $37^{\circ} \mathrm{C}$. At the end of the incubation period, nonadherent bacteria were removed from the surfaces by gently washing with PBS $(\mathrm{pH}$ 7.4) three times and the adherent bacteria were fixed with $2.5 \%$ (v/v) glutaraldehyde in $0.1 \mathrm{M}$ DPBS for $20 \mathrm{~min}$, dehydrated in ethanol series, and rinsed with HMDS for SEM analysis.

\section{Results}

The results of PEO coating, characterization, and cellular responses of Ti surfaces were given below.

\subsection{Coating of Ti implants with PEO nanofibers}

In this study, electrospinning was used for the modification of Ti surfaces by the PEO nanofibers. PEO having a wide range of molecular weight is nontoxic, hydrophilic, and biocompatible polymer. In this study, we used PEO at 600,000 Da molecular weight. Since PEO is highly soluble in water, it is necessary to crosslink it for obtaining insoluble nanofiber mats. Here, we chose UV-induced crosslinking in the presence of pentaerythritol triacrylate (PETA) [29]. In our previous study, electrospinning and crosslinking conditions were optimized in order to obtain continuous, bead-free, and insoluble nanofibers [23]. In this study, the PEO coating was performed on Ti samples according the previous results (Table 2).

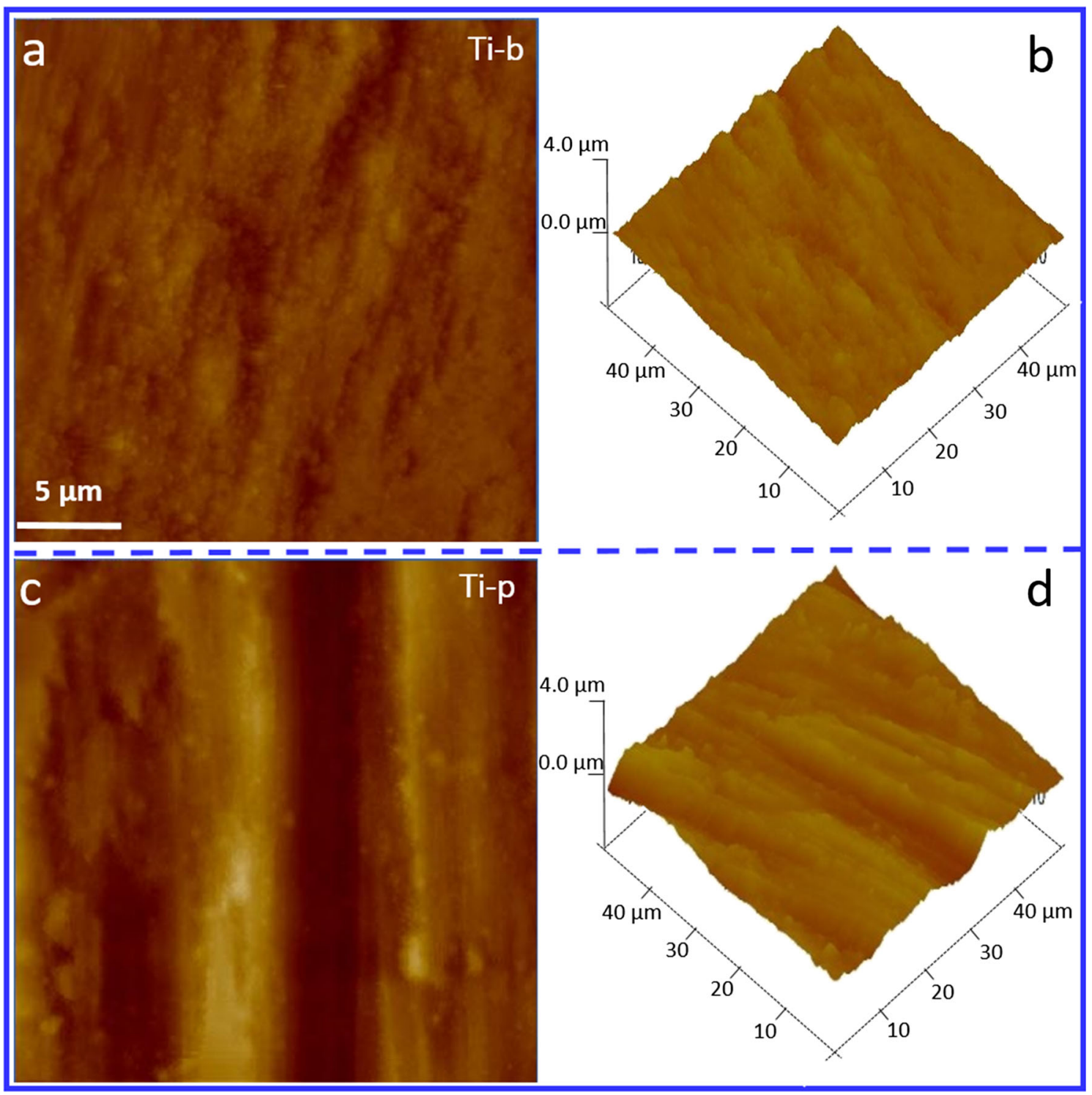

Fig. 1 AFM images of (a, b) Ti-b and (c, d) Ti-p surfaces. a and c show 2D images, b and d show 3D images 


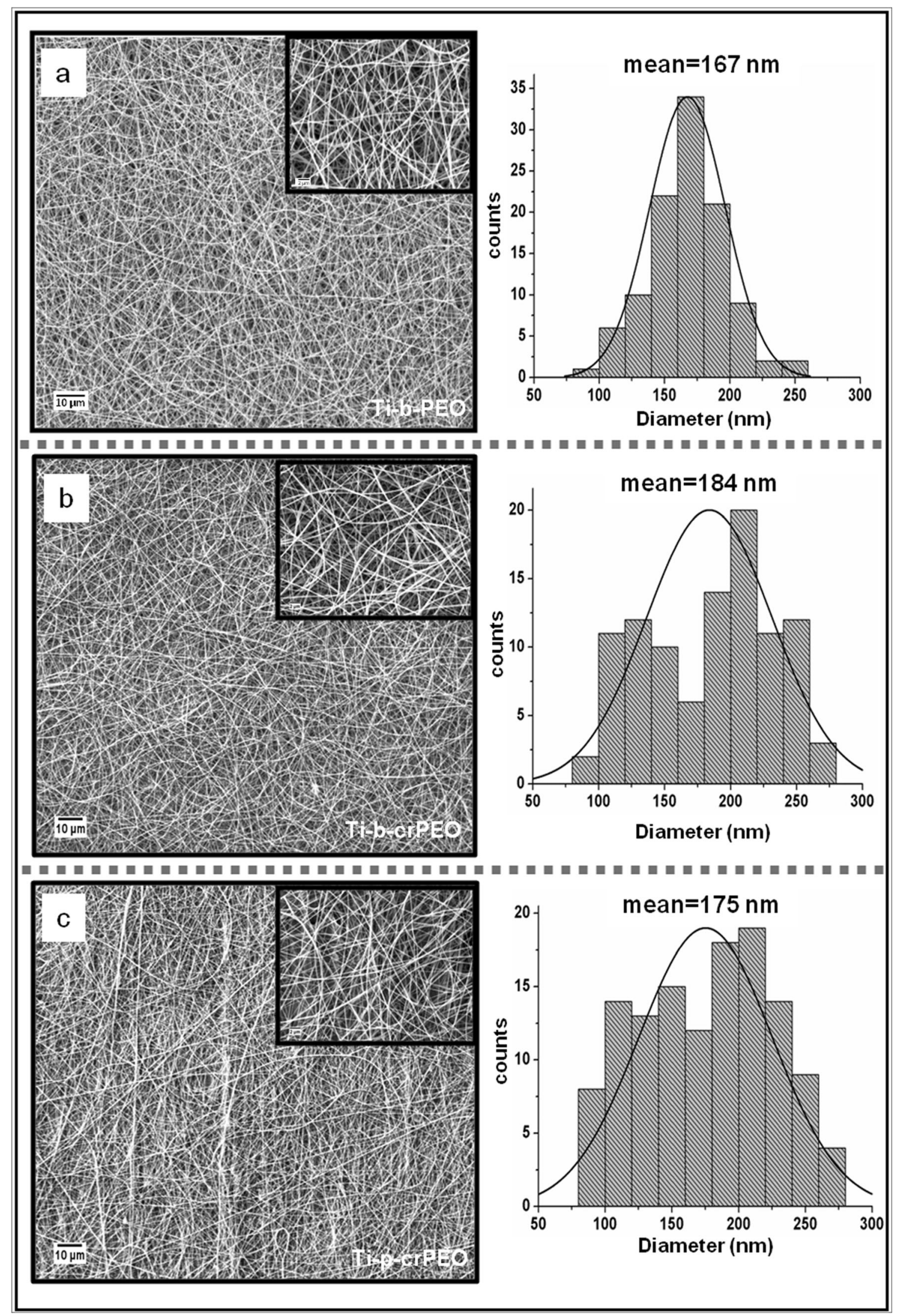

Fig. 2 SEM images of a Ti-b-PEO, b Ti-b-crPEO, c Ti-p-crPEO and their diameter distributions (2 KX, upper right images: 10KX)

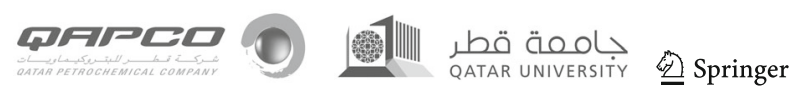


Fig. 3 AFM images of (a, b) Ti-bcrPEO and (c, d) Ti-p-crPEO

(upper right images show higher magnifications); SEM and AFM images of (e, f) Ti-b-crPEO and $(g, h)$ Ti-p-crPEO surfaces after treating with distilled water. Left column shows 2D images, right column shows 3D images
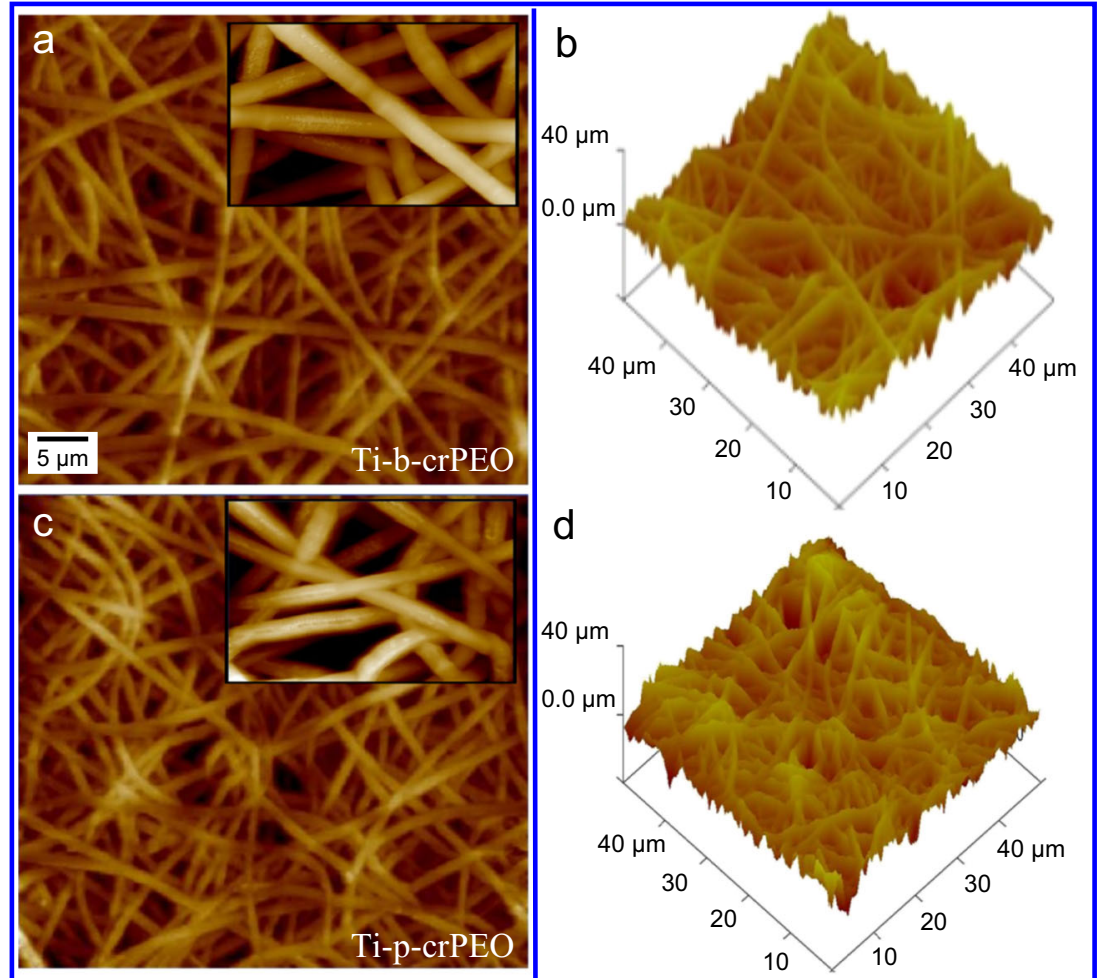

d
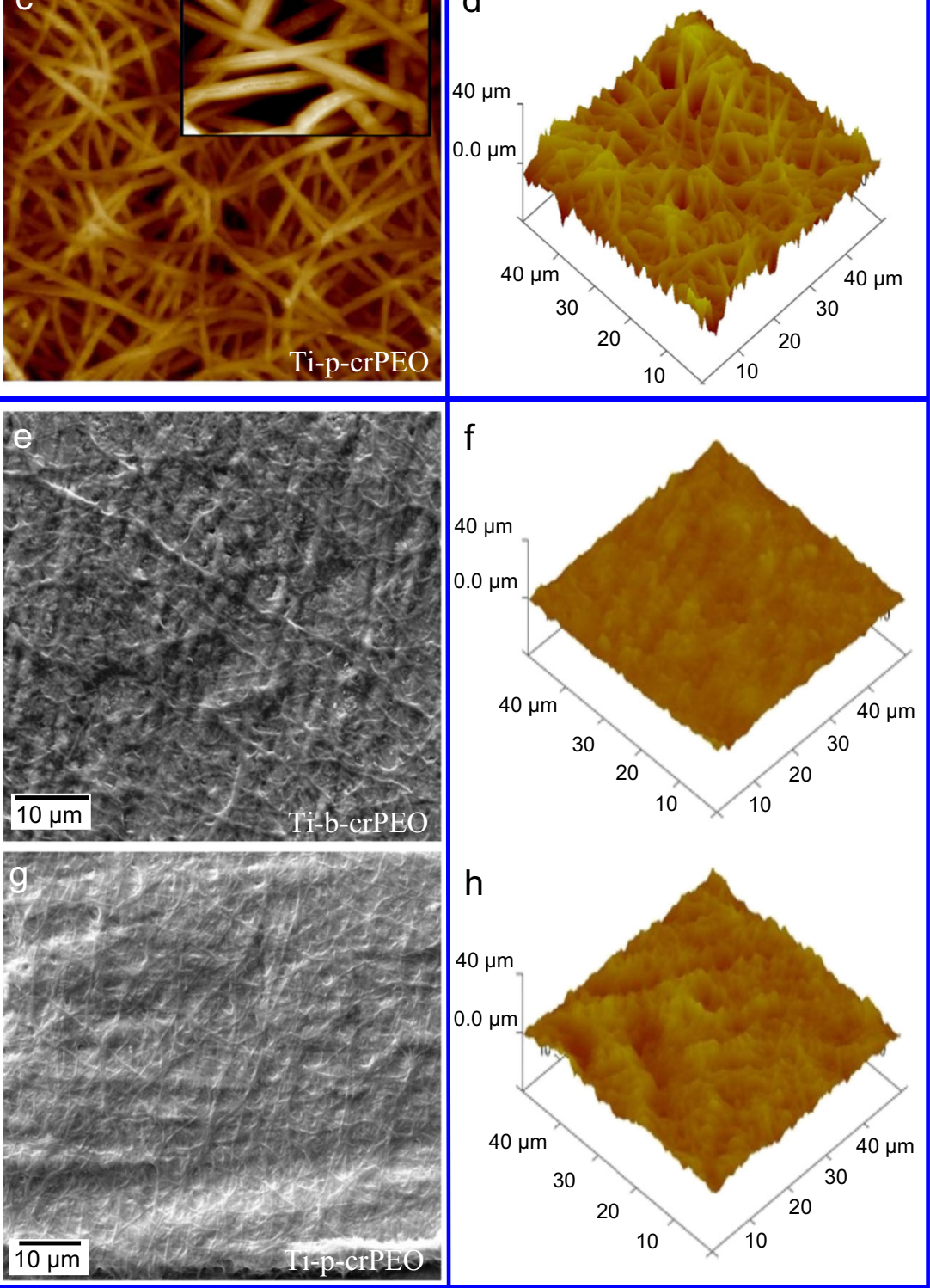
Table 3 Water contact angles and surface roughness (measured by perthometer) of titanium samples

\begin{tabular}{lll}
\hline Samples & $\begin{array}{l}\text { Water } \\
\text { contact } \\
\text { angles }\left(^{\circ}\right)\end{array}$ & $\begin{array}{l}\text { Roughness } \\
(\mu \mathrm{m})\end{array}$ \\
\hline Ti-b & 49 & 0.18 \\
Ti-p & 65 & 0.28 \\
Ti-b-crPEO & 12 & nd \\
Ti-p-crPEO & 20 & nd \\
\hline
\end{tabular}

\subsection{Surface characterization}

In order to investigate surface topographies of Ti samples, SEM and AFM analyses were done. Figure 1 shows the topographies of bare Ti surfaces (Ti-b) and sandpapered Ti surfaces (Ti-p). When comparing with Ti-b (Fig. 1a, b), rougher surface texture of Ti-p drew the attention (Fig. 1c, d). Perthometer analysis also revealed that the surface roughness increased from $0.18 \mu \mathrm{m}$ on Ti-b to $0.28 \mu \mathrm{m}$ on Ti-p surfaces.

To determine the effect of PETA on the fiber morphology and diameter, PEO nanofibers not including PETA were also collected on Ti-b surfaces. Figure 2 shows the SEM images of uncrosslinked and crosslinked PEO nanofibers on Ti strips.
The images reveal that the fibers exhibited similar morphology in all samples. While the uncrosslinked PEO nanofibers on Ti-b had a diameter of $167 \pm 29 \mathrm{~nm}$ (Fig. 2a), the crosslinked fibers on Ti-b and Ti-p had diameters of $184 \pm 48 \mathrm{~nm}$ and 175 $\pm 50 \mathrm{~nm}$, respectively (Fig. 2b, c). The results exhibited that the presence of PETA in the electrospinning solution did not cause any significant effect on the fiber diameter and morphology. However, the nanofibers exhibited narrower diameter distribution in the absence of PETA (Fig. 2a). The AFM images of crosslinked-PEO nanofiber coated Ti-b (Ti-b-crPEO) (Fig. 3a, b) and Ti-p (Ti-p-crPEO) (Fig. 3c, d) surfaces also disclosed that there was no significant difference between fiber morphologies on both surfaces. Nevertheless, the wavy structures observed in the fiber arrangement on Ti-p-crPEO indicated that the fiber morphology was affected by increased surface roughness (Fig. 3d).

Some of the Ti-b-crPEO and Ti-p-crPEO samples were immersed into distilled water $\left(37^{\circ} \mathrm{C}\right)$ for $24 \mathrm{~h}$ and dried at room temperature in order to determine whether stable coating was available or not. After drying period, fibers fused with each other by generating membrane-like form on the Ti surfaces (Fig. 3e-h). This is important since such a coating provided an isolated environment that would inhibit/reduce
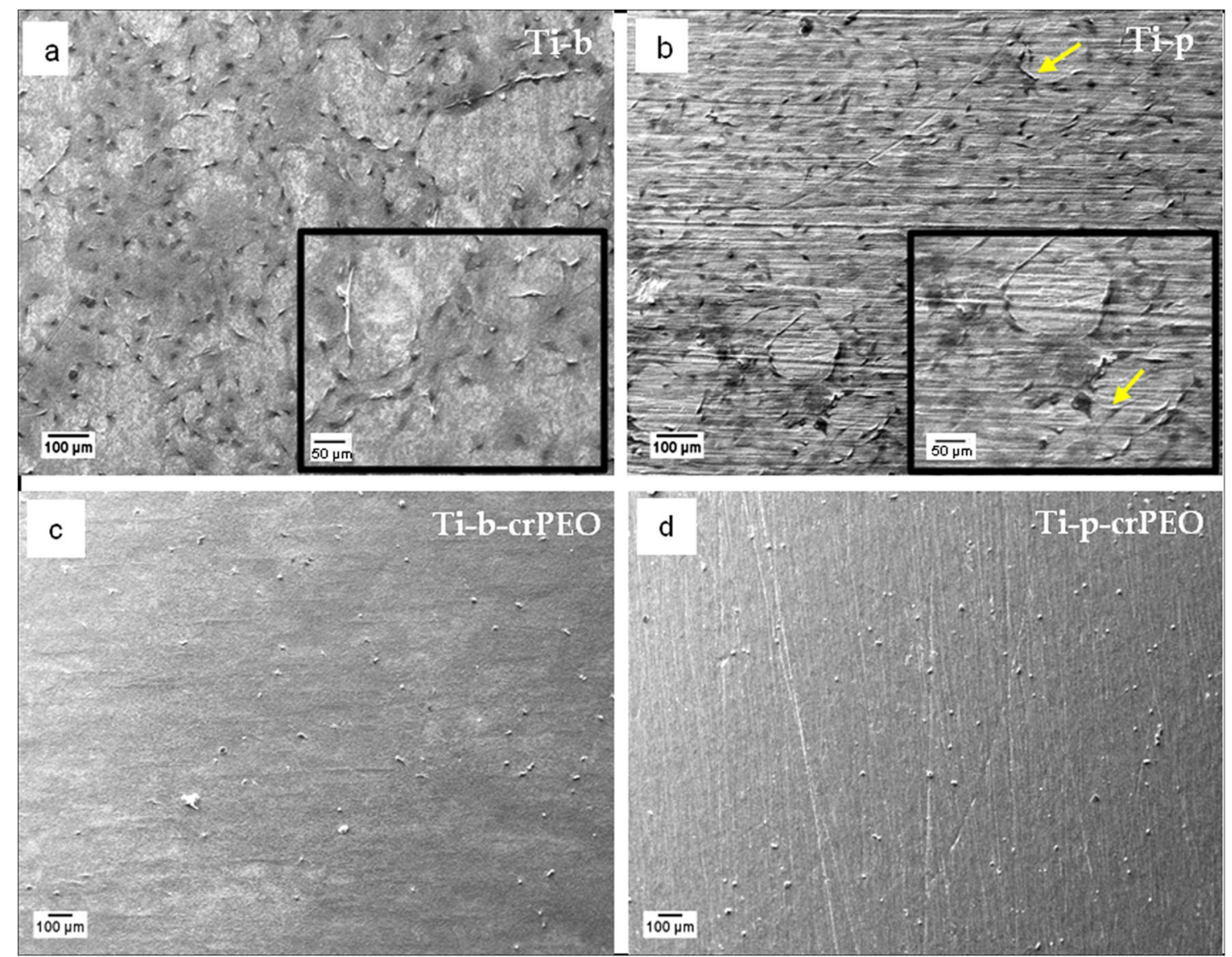

Fig. 4 SEM images of MC3T3-E1 preosteoblasts on a Ti-b, b Ti-p, $\mathbf{c}$ Ti-b-crPEO, and $\mathbf{d}$ Ti-p-crPEO $(\times 250$, bottom right images: $\times 500)$ at the end of the $4 \mathrm{~h}$ of incubation (yellow arrows show the cells with spreaded morphology) 
interactions of the cells and the bacteria with the implant surfaces. The fiber coating on Ti-p (Fig. 3g, h) was more stable than that of Ti-b (Fig. 3e, f). Since Ti-p had higher number of attachment points due to its rougher surface, the fibers exhibited better attachment onto Ti-p surfaces.

The water contact angles of coated and uncoated surfaces were measured by sessile drop method immediately after deionized water drop contacted with the surfaces. The contact angle increased from $49^{\circ}$ (Ti-b) to $65^{\circ}$ (Ti-p) with increasing surface roughness and decreased significantly to $12^{\circ}$ and $20^{\circ}$ after coating with PEO nanofibers, respectively (Table 3 ).

\subsection{Adhesion of MC3T3-E1 preosteoblasts and $S$. epidermidis onto the Ti surfaces}

In this study, the cellular attachment on bare, sandpapered, and PEO nanofiber-coated Ti surfaces were investigated and compared. SEM images belonging to the 4 th hour of cell culture were taken to visualize the initial adhesion of preosteoblasts on the surfaces (Fig. 4a, b). It was obvious that both of the uncoated surfaces (Ti-b and Ti-p) supported cell attachment and the cells began to spread at the end of the $4 \mathrm{~h}$ of incubation on the surfaces by using their cytoplasmic extensions. However, there were less number of the cells with spherical morphology on the Ti-p surfaces (Fig. 4b) when compared with Ti-b surfaces (Fig. 4a).

SEM images of MC3T3-E1 cells on Ti-b-crPEO and Ti-pcrPEO revealed that the number of the attached cells substantially reduced when compared with the uncoated ones (Fig. $4 c, d)$. At the end of the $4 \mathrm{~h}$ of cell culture, the presence of a few cells with spherical morphology showed that the cell attachment requiring for cell-material was not achieved. This result shows the PEO directly affected and significantly inhibited the attachment of the preosteoblastic cells.

Figure 5 a shows the MTT results of the cells cultured on Ti-b, Ti-p, Ti-b-crPEO, Ti-p-crPEO, and TCPS for 48-h
Fig. 5 Mitochondrial activities of MC3T3-E1 cells proliferated on a) Ti-b, Ti-p, Ti-b-crPEO, Ti-pcrPEO, and TCPS for $48 \mathrm{~h}$ (statistically significant differences, $n=3 * p<0.005$, $* * p<0.01, * * * p<0.001-\mathrm{Ti}-\mathrm{b}$ is control; ${ }^{+} p<0.005,{ }^{++} p<0.01$, ${ }^{+++} p<0.001-$ Ti-p is control; ${ }^{\circ} p<0.005,{ }^{\circ} p<0.01$,

${ }^{\text {ooo }} p<0.001-$ Ti-b-crPEO is

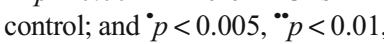
$\cdots p<0.001$-Ti-p-crPEO is control); b) Ti-b and Ti-b-crPEO for 28 days (statistically significant differences, $n=3$ $* * * p<0.001$; Ti-b is control)
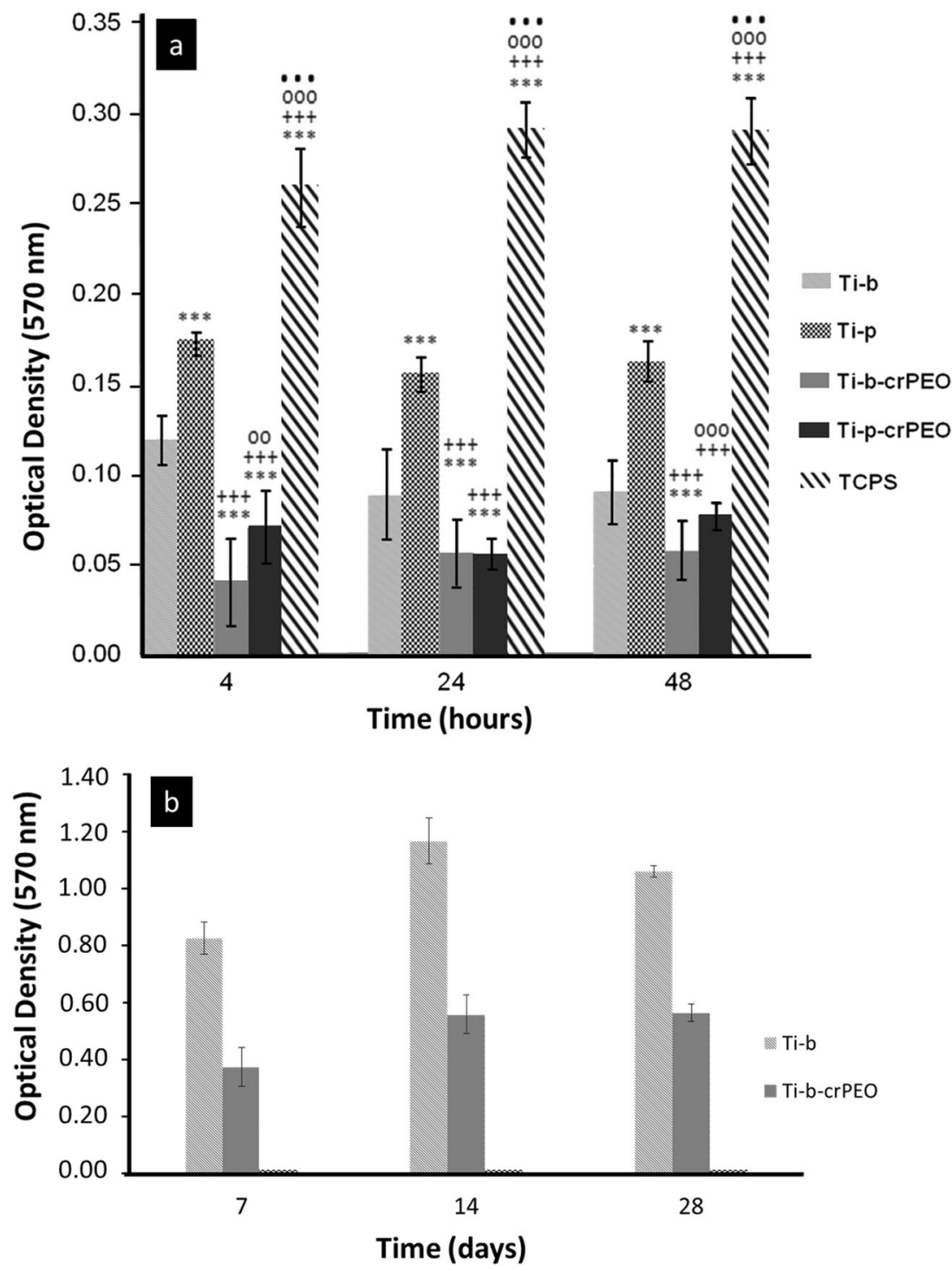
culture period. Mitochondrial activities of the cells on the Ti-p surfaces were higher than that of the cells on Ti-b. The highest activity was observed for the cells on TCPS. The MTT absorbance values decreased on PEO-coated surfaces depending upon decreasing cellular activity. Figure $5 \mathrm{~b}$ shows that the effect of PEO coating sustained for the long term (28 days).

In the following part of the study, $S$. epidermidis was used for assessing the bacterial attachment and colonization on the Ti-b and Ti-b-crPEO surfaces. Figure 6 a shows the SEM images of $S$. epidermidis (+) on Ti-b and Ti-b-crPEO after $24 \mathrm{~h}$ of incubation. According to the images, the bacteria attached and proliferated intensively and colonized on the uncoated samples. On the contrary, Ti-b-crPEO surface reduced bacterial attachment significantly due to the repellent effect of PEO's polymer chains. Figure $6 \mathrm{~b}$ also supported that for both of the bacteria.

\section{Discussion}

Infection remains a major obstacle to the long-term performance of many implanted devices. The initial stage in the pathogenesis of the infection to the implanted device is the bacterial adhesion. It is known that a variety of factors affect bacterial adhesion, i.e., the presence of adhesive molecules, dissolved proteins, and surface properties of both the bacteria and the implant material [4, 30]. Among them, the properties of an implant such as its chemical composition, roughness, wettability, and steric hindrance are all thought to be important in the initial bacterial response to a material surface [31]. The same properties also affect the mammalian cell response, i.e., adhesion and proliferation behavior in the similar manner. As indicated firstly by Gristina [31], there is a race for the implant
Fig. 6 a SEM images of $S$. epidermidis colonies on Ti-b $(\times 500$, bottom right image; 15 $\mathrm{KX})$ and Ti-b-crPEO $(1 \mathrm{KX})$ at the end of the $24 \mathrm{~h}$ of incubation. $\mathbf{b}$ Comparison of attachment behaviors of S. epidermidis (-) and $S$. epidermidis (+) on Ti surfaces (a)
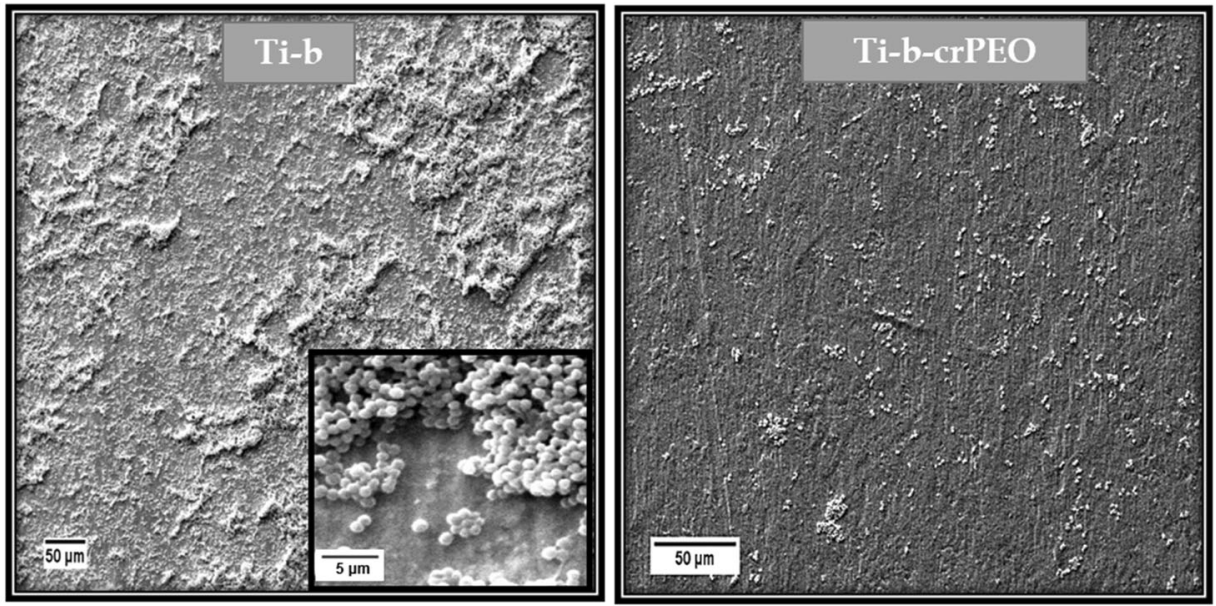

(b)

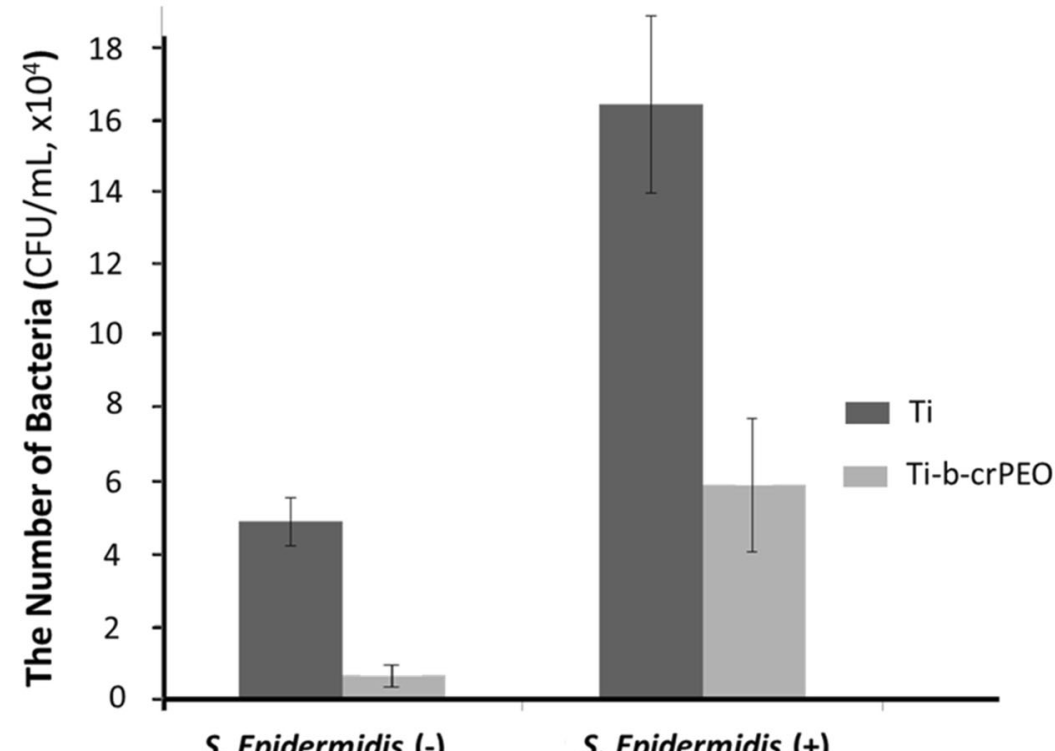

S. Epidermidis (-) 
surface between bacteria and tissue cells. If the race is won by bacteria, tissue cells will not be able to establish themselves on implant surface. Furthermore, bacterial attachment and subsequent colonization lead to biofilm formation that results infection [3].

Several surface modifications have been developed for the purpose of discouraging microbial adhesion on the implant surfaces. In general, this can be achieved by either repelling or killing the approaching cells. The repelling of bacteria was performed with hydrogel coatings mostly based on immobilized PEO [12-15]. In this study, unlike these methods, stable PEO nanofibers are successfully coated onto Ti surfaces by applying sequential electrospinning and crosslinking processes. For this approach, the water solution of PEO and PETA was electrospun and then, crosslinking process was realized under UV irradiation. We carried out optimization and characterization studies for UV-crosslinked PEO nanofibers in our previous study [23], so we did not perform further characterizations in the presented study. Here, we modified the procedure reported by Zhou et al. for the preparation of UVcrosslinked electrospun PEO fibers [29]. During the electrospinning process, PETA was not excluded as reported before. PETA took a hydrogen atom from PEO when it was excited by UV light, and PEO and PETA radicals formed. PEO radicals attacked to the $\mathrm{C}=\mathrm{C}$ bond of PETA to initiate the polymerization of PETA. Termination occurred by radical coupling and crosslinks formed between PEO and PETA. As a result, we obtained stable and permanent PEO coating on both bare and sandpapered Ti strips. Prior to coating, we did not apply any etching procedure with chemicals.

The anticellular characteristics of PEO coatings were investigated by using MC3T3-E1 preosteoblasts in fibroblastic morphology as a model tissue cell and S. epidermidis strain as a model of pathogenic bacteria. The higher number of spreaded preosteoblasts on Ti-p surfaces indicated that the cell attachment was enhanced on Ti-p surfaces. It could also be concluded that the cells adapted more easily to the Ti-p surfaces and their metabolic activities were enhanced in favor of surface roughness. Since the surface roughness of Ti-p implants increased, protein absorption was improved more accordingly on the rougher surface. Thus, the number of focal adhesion points became higher level and this led to increased cellular attachment and mitochondrial activity. Many studies have shown the higher adhesion ability of osteoblasts on rough $\mathrm{Ti}$ and $\mathrm{Ti}-6 \mathrm{Al}-4 \mathrm{~V}$ compared with smooth $\mathrm{Ti}$ and $\mathrm{Ti}-$ 6Al-4V surfaces [32, 33]. Neoh et al. [3] reported that Ti surfaces having various surface roughness had a different impact on osteoblast adhesion and the cell attachment was improved with increasing surface roughness. In contrast, Jayaraman et al. [34] compared a sandblasted, an acid-etched, and a grooved surface through in vitro systems. The grooved surface supported better osteoblastic cell adhesion and proliferation than that of the rough surfaces.
As expected, the cellular and bacterial attachment significantly reduced on both Ti-b-crPEO and Ti-p-crPEO due to the presence of PEO fibers. This result can be attributed to the steric barrier, excluded volume effect, and osmotic repulsion exerted by highly hydrated and flexible PEO chains.

\section{Conclusion}

The focus of this study was to propose a simple and effective anticellular coating method for metallic implants. This is why a two-step process including electrospinning and crosslinking was employed. At first, titanium surfaces were effectively coated with smooth and uniform PEO nanofibers. Then, stable PEO coating was obtained by crosslinking PEO nanofibers with PETA in the presence of UV irradiation. The comparative adhesion behavior of the mammalian cells and the bacteria on the different Ti surfaces, i.e., bare, sandpapered, and PEO nanofiber-coated surfaces, was investigated. PEO-coated Ti surfaces substantially reduced the cellular attachment without the need for further modifications. However, as shown in the study, such hydrophilic surfaces also prevented the adhesion of preosteoblastic cells which is necessary for the implanttissue integration (osteointegration). Hence, in order to obtain successful implants which will inhibit bacterial adhesion and encourage osteointegration at the same time, further modifications are required. We will focus on this challenge in our following studies by modifying PEO with osteoblast-specific biosignal molecules.

\section{References}

1. S. Cecconi, M. Mattioli-Belmonte, S. Manzotti, M. Orciani, A. Piccioli, A. Gigante, Bone-derived titanium coating improves in vivo implant osseointegration in an experimental animal model. J. Biomed. Mater. Res. B Appl. Biomat. 102, 303-310 (2014)

2. S. Ferraris, A. Venturello, M. Miola, A. Cochis, L. Rimondini, S. Spriano, Antibacterial and bioactive nanostructured titanium surfaces for bone integration. Appl. Surf.Sci. 311, 279-291 (2014)

3. K.G. Neoh, X. Hu, D. Zheng, E.T. Kang, Balancing osteoblast functions and bacterial adhesion on functionalized titanium surfaces. Biomaterials 33, 2813-2822 (2012)

4. R. Ravichandran, C.C.H. Ng, S. Liao, D. Pliszka, M. Raghunath, S. Ramakrishna, C.K. Chan, Biomimetic surface modification of titanium surfaces for early cell capture by advanced electrospinning. Biomed. Mater. 7, 015001 (2012)

5. W. Zimmerli, Prosthetic-joint-associated infections. Best Prac.t Res. Clin. Rheumatol. 20, 1045-1063 (2006)

6. D. Campoccia, L. Montanaro, C.R. Arciola, The significance of infection related to orthopedic devices and issues of antibiotic resistance. Biomaterials 27, 2331-2339 (2006)

7. A.G. Karakeçili, M. Gümüsderelioğlu, Comparison of bacterial and tissue cell initial adhesion on hydrophilic/hydrophobic biomaterials. J. Biomater. Sci. Polym. Ed. 13, 185-196 (2002)

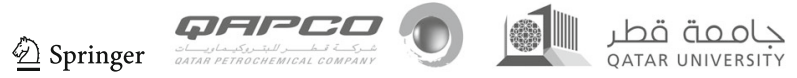


8. C. von Eiff, G. Peters, C. Heilmann, Pathogenesis of infections due to coagulase-negative staphylococci. Lancet Infect. Dis. 2, 677-685 (2002)

9. S. Nagaoka, H. Kawakami, Inhibition of bacterial adhesion and biofilm formation by a heparinized hydrophilic polymer. ASAIO J. 41, M365-M368 (1995)

10. Y. Mori, S. Nagaoka, H. Takiuchi, T. Kikuchi, N. Noguchi, H. Tanzawa, Y. Noishiki, A new antithrombogenic material with long polyethyleneoxide chains. Trans. Am. Soc. Artif. Intern. Organs 28, 459-463 (1982)

11. L. Ruiz, E. Fine, J. Voros, S.A. Makohliso, D. Leonard, D.S. Johnston, M. Textor, H.J. Mathieu, Phosphorylcholine-containing polyurethanes for the control of protein adsorption and cell attachment via photoimmobilized laminin oligopeptides. J. Biomater. Sci. Polym. Ed. 10, 931-955 (1999)

12. N.P. Desai, S.F.A. Hossainy, J.A. Hubbell, Surface-immobilized polyethylene oxide for bacterial repellence. Biomaterials 13, 417420 (1992)

13. L.G. Harris, S. Tosatti, M. Wieland, M. Textor, R.G. Richards, Staphylococcus aureus adhesion to titanium oxide surfaces coated with non-functionalized and peptide-functionalized poly(L-lysine)grafted-poly(ethylene glycol) copolymers. Biomaterials 25, 41354148 (2004)

14. Y. Su, L. Wang, X. Yang, A simple swelling and anchoring method for preparing dense and stable poly(ethylene oxide) layers on polystyrene surfaces. Appl. Surf. Sci. 254, 4606-4610 (2008)

15. P. Kingshott, J. Wei, D. Bagge-Ravn, N. Gadegaard, L. Gram, Covalent attachment of poly(ethylene glycol) to surfaces, critical for reducing bacterial adhesion. Langmuir 19, 6912-6921 (2003)

16. F. Zhang, E.T. Kang, K.G. Neoh, P. Wang, K.L. Tan, Surface modification of stainless steel by grafting of poly(ethylene glycol) for reduction in protein adsorption. Biomaterials 22, 1541-1548 (2001)

17. K.D. Park, Y.S. Kim, D.K. Han, Y.H. Kim, E.H. Lee, H. Suh, K.S. Choi, Bacterial adhesion on PEG modified polyurethane surfaces. Biomaterials. 19, 851-859 (1998)

18. L.K. Ista, H. Fan, O. Baca, G.P. Lopez, Attachment of bacteria to model solid surfaces: oligo(ethylene glycol) surfaces inhibit bacterial attachment. FEMS Microbiol. Lett. 142, 59-63 (1996)

19. A. Razatos, Y.-L. Ong, F. Boulay, D.L. Elbert, J.A. Hubbell, M.M. Sharma, G. Georgiou, Force measurements between bacteria and poly(ethylene glycol)-coated surfaces. Langmuir. 16, 9155-9158 (2000)

20. P. Kingshott, H. Thissen, H.J. Griesser, Effects of cloud-point grafting, chain length, and density of PEG layers on competitive adsorption of ocular proteins. Biomaterials 23, 2043-2056 (2002)

21. M. Malmsten, K. Emoto, J.M. Van Alstine, Effect of chain density on inhibition of protein adsorption by poly(ethylene glycol) based coatings. J. Colloid Interface Sci. 202, 507-517 (1998)
22. A.R. Denes, E.B. Somers, A.C.L. Wong, F. Denes, 12-crown-4 ether and tri(ethylene glycol) dimethyl-ether plasma-coated stainless steel surfaces and their ability to reduce bacterial biofilm deposition. J. Appl. Polym. Sci. 81, 3425-3438 (2001)

23. M. Șimşek, M. Çapkın, A. Karakeçili, M. Gümüsderelioğlu, Chitosan and polycaprolactone membranes patterned via electrospinning: effect of underlying chemistry and pattern characteristics on epithelial/fibroblastic cell behavior. J. Biomed. Mater. Res. A 100, 3332-3343 (2012)

24. M. Gümüşderelioğlu, S. Dalkıranoğlu, R.S.T. Aydın, S. Çakmak, A novel dermal substitute based on biofunctionalized electrospun PCL nanofibrous matrix. J. Biomed. Mater. Res. A 98A, 461-472 (2011)

25. W. Meng, S.Y. Kim, J. Yuan, J.C. Kim, O.H. Kwon, N. Kawazoe, G. Chen, Y. Ito, I.K. Kang, Electrospun PHBV/collagen composite nanofibrous scaffolds for tissue engineering. J. Biomater. Sci. Polym. Ed. 18, 81-94 (2007)

26. Y.-f. Wang, H.-f. Guo, D.-j. Ying, Multilayer scaffold of electrospun PLA-PCL-collagen nanofibers as a dural substitute. J Biomed Mater Res B Appl Biomater 101, 1359-1366 (2013)

27. S. Çakmak, A.S. Çakmak, M. Gümüşderelioğlu, RGD-bearing peptide-amphiphile-hydroxyapatite nanocomposite bone scaffold: an in vitro study. Biomed. Mater. 8, 045014 (2013)

28. L.L. Li, L.M. Wang, Y. Xu, L.X. Lv, Preparation of gentamicinloaded electrospun coating on titanium implants and a study of their properties in vitro. Arch. Orthop. Trauma Surg. 132, 897-903 (2012)

29. C. Zhou, Q. Wang, Q. Wu, UV-initiated crosslinking of electrospun poly (ethylene oxide) nanofibers with pentaerythritol triacrylate: effect of irradiation time and incorporated cellulose nanocrystals. Carbohydr. Polym. 87, 1779-1786 (2012)

30. D. Cunliffe, C.A. Smart, C. Alexander, E.N. Vulfson, Bacterial adhesion at synthetic surfaces. Appl. Environ. Microbiol. 65, 4995-5002 (1999)

31. A.G. Gristina, Biomaterial-centered infection: microbial adhesion versus tissue integration. Science 237, 1588-1595 (1987)

32. J. Lincks, B.D. Boyan, C.R. Blanchard, C.H. Lohmann, Y. Liu, D.L. Cochran, D.D. Dean, Z. Schwartz, Response of MG63 osteoblast-like cells to titanium and titanium alloy is dependent on surface roughness and composition. Biomaterials 19, 2219-2232 (1998)

33. J.L. Ong, D.L. Carnes, H.L. Cardenas, R. Cavin, Surface roughness of titanium on bone morphogenetic protein-2 treated osteoblast cells in vitro. Implant. Dent. 6, 19-24 (1997)

34. M. Jayaraman, U. Meyer, M. Bühner, U. Joos, H.P. Wiesmann, Influence of titanium surfaces on attachment of osteoblast-like cells in vitro. Biomaterials 25, 625-631 (2004) 